\title{
Recycling as Habitual Behavior: The Impact of Habit on Household Waste Recycling Behavior in Thailand
}

\author{
Achapan Ittiravivongs ${ }^{1}$ \\ ${ }^{1}$ Graduated School of Business and Commerce, Keio University, Tokyo, Japan \\ Correspondence: Achapan Ittiravivongs, Graduated School of Business and Commerce, Keio University, \\ 2-15-45 Mita, Minato-ku, Tokyo, Japan. Tel: 81-3-5427-1517. E-mail: achapan_i@yahoo.com
}

Received: December 27, $2011 \quad$ Accepted: January 31, $2012 \quad$ Published: May 1, 2012

doi:10.5539/ass.v8n6p74 URL: http://dx.doi.org/10.5539/ass.v8n6p74

The research is financed by 'Grant for the advancement of research 2011', Graduated School of Business and commerce, Keio University.

\begin{abstract}
This research aims to permit a better understanding of factors influencing recycling behavior of Thai households in a habitual perspective. The study applied theory of interpersonal as critical framework and investigated the role of habit on recycling involvement of 381 samples in Bangkok. The outcomes indicated that recycling behavior was significantly predicted by recycling intention, habit, recycling ability, facility condition, and adequacy of recycling information, in order of strength. A trade-off relationship between recycling habit and intention was also found. With higher degree of habit, recycling behavior is subjected to be less depended on intention. In addition, relations of behavior-intention and behavior-facility condition were found significantly different across habit levels. Recycling behavior is likely to be less related to recycling intention and facility condition for strong habit group. The results suggested that recycling habit is an important issue needed to be considered as a notable factor influencing household recycling behavior.
\end{abstract}

Keywords: solid waste, household recycling, habit, interpersonal behavior, Thailand

\section{Introduction}

The solid waste generation in Thailand had risen from 30,640 tons per day in 1993 to 41,410 tons per day in 2009. Of total generated waste, less than $40 \%$ has been properly managed (Pollution Control Department, 1993-2009). The excessive solid waste generation without proper treatments caused a number of negative impacts and became an emerging social and environmental concern. As one of waste management strategies to reduce materials that need to be disposed and to convert valuable materials that would otherwise end up as waste into valuable resources, recycling has been broadly promoted for over decades. However, the recycling rate in Thailand is rather low. Only approximately $20 \%$ of over 15 million tons of annual generated waste is being recycled, whereas it is estimated that the potential recyclable waste in Thailand is as high as 40-60\% (Shapkota, Coowanitwong, Visvanathan, \& Trankler, 2006).

The achievement of recycling programs relies largely on the dynamic and sustained involvement of people. Thus, it is important to understand factors that induce people to recycle. Among previous studies regarding factors determining recycling behavior, one issue that has been rarely concentrated is the repetitive characteristic of recycling conduct. According to Ronis et al. (1989), an extensive repetition could develop automatic processes which result in a reduction in the amount of cognition needed to make in decision and further build up a habit. That is, recycling could be considered as a form of habitual behavior which is performed based on habit rather than consciousnesses or constantly reasons. The role of habit on pro-environmental behavior is noteworthy as it can override the attitudinal and subjective norm components (Laroche, Toffoli, Kim, \& Muller, 1996). Considering a promising role of habit, the present study purposes to investigate impacts of recycling habit on recycling behavior of Thai people as well as to examine a significant difference of relationship between the 
predictors and recycling behavior across habit levels.

\section{Habit and Recycling Behavior}

Though the previous studies of understanding role of recycling habit were not recognizable, habit of recycling has been verified to be a significant factor in the literatures. Knussen and Yule (2008) found that lack of recycling habit made significant contributions to the variance of intention to recycle and moderated the attitude-intention relationship. Carrus et al. (2008) also indicated in their study of emotional, habit, and rational choice in the case of recycling that the past behavior (as a representative of habit) significantly predicted intention to recycle. Most of previous researches posited habit as a predictor of recycling intention or desire which further influences the actual behavior. The present study, however, aims to investigate the role of habit under a different framework. Instead of examining the role of habit on the recycling intention, this study desires to investigate the direct role of recycling habit on the actual recycling action.

The relationship among habit and behavior was formalized by Triandis (1977). In his theory of interpersonal behavior, a behavior can be predicted partly by the situational constraints and conditions, party by the habitual responses, and partly by the intention. Habit responses are relatively stable behavioral patterns and tends to result from automatic process as opposed to controlled processes like consciously made decisions (Shiffrin \& Schneider, 1977). In Triandis's model, the probability of an act $\left(\mathrm{P}_{\mathrm{a}}\right)$ is a weighted function of habit $(\mathrm{H})$ and behavior intention (I), multiplied by facilitating conditions $(\mathrm{F})$. The relationship can be expressed as:

$$
\mathrm{P}_{\mathrm{a}}=\left(\mathrm{w}_{\mathrm{H}} * \mathrm{H}+\mathrm{w}_{\mathrm{I}} * \mathrm{I}\right) * \mathrm{~F}
$$

The probability of an act therefore depends on 1) the strength of the habit of emitting the behavior which, according to Triandis (1977), indexed by the number of times the behavior has already occurred in the history of the organism, 2) the behavioral intention to emit the behavior which is determined by social influence, self-satisfaction, and the value of the perceived consequence of the behavior, and 3) the presence or absence of conditions that facilitate performance of the behavior. The habit's weight and intention's weight are supposed to be negatively correlated. New behavior is assumed to be completely under the control of intentions. As the behavior occurs more frequently, $\mathrm{w}_{\mathrm{H}}$ increases while $\mathrm{w}_{\mathrm{I}}$ declines. That is, people with weak or no habits tend to act on their intentions, whereas people with strong habits continue to respond at past performance levels regardless of their intentions (Verplanken, Aarts, van Knippenberg, \& van Knippenberg, 1994; Ouellette \& Wood, 1998; Danner, Aarts, \& de Vries, 2008). This research applied the theory of interpersonal behavior as the main framework and purposes to; 1) investigate the effect of recycling habit on recycling behavior, 2) examine the trade-off relationship between recycling intention and the habit, and 3) explore a significant distinction of correlation between recycling predictors and recycling behavior across strong and weak habit levels.

\section{Research Design}

\subsection{Instrument Development}

The data of this research were collected from personal interviews based on a structured questionnaire, designed follow the previous literatures (Boldero, 1995; Taylor \& Todd, 1995; Barr, 2002; Chu \& Chiu, 2003; Tonglet, Phillips, \& Read, 2004; Valle, Reis, Menezes, \& Rebelo, 2004; Chen \& Tung, 2010). To examine the quality of the questionnaire items, pre-tests were carried out two times in November and October 2010 prior to the main survey which conducted during the period of December 2010 to January 2011. Participants in the pre-tests were 80 Thai citizens who have been resided in Bangkok not less than 90 days. The internal consistency of question dimensions was measured by Conbach's alpha coefficient which indicates the degree to which a set of items measures a single unidimensional latent construct, values from 0 to 1 . Values above 0.7 indicate a good internal consistency (Cronbach, 1951). The results of the second pre-test were satisfied in every question with alpha coefficients over 0.71 . The verified questionnaire survey consisted with 3 parts; 1) questions regarding respondents' profile, 2) questions regarding recycling behavior and intention, and 3) six-point scales question items of promising explanatory factors (strongly disagree $=1$ to strongly agree $=6$ ). The definitions of technical terms using in the questionnaire were clarified to the respondents prior to the interview to avoid error answers from misunderstanding.

\subsection{Sampling and Data Collection}

The Bangkok capital city was selected for the study area. The target population was individuals who have been inhabited in Bangkok at least 90 days. Multi-stages sampling method was applied to gather research samples. 
Features of total 50 districts (khet) in Bangkok were firstly examined in the first step. The inner-Bangkok area, which is classified as residential and business area (BMA data center, 2009), was selected as the interest group as the research objective is to study the waste recycling behavior of households. Pathumwan district was randomly selected from 21 districts located in inner-Bangkok in the following stage by drawing lots. Next, the required sample size was calculated by using Krejcie and Morgen's formula (Krejcie \& Morgan, 1970).

$$
n=\frac{x^{2} N=(1-R)}{d^{2}(N-1)+x^{2} R(1-F)}
$$

Where $n=$ required sample size, $X^{2}=$ table value of chi-square for 1 degree of freedom at the $95 \%$ confidence level (3.841), $N=$ population size, $P=$ population proportion (assumed to be .50 since this would provide the maximum sample size), and $d=$ degree of accuracy expressed as a proportion .05 or $5 \%$ margin error. According to the population and housing statistic provided by Department of Provincial Administration (2009), Pathumwan district has a population $(N)$ of 58,858 people (male 27,463; female 31,395) as of 2009. Based on the sampling formula, 381 samples were required at 5\% margin error. In the final stage, the number of sample required for 4 sub-districts (kwaeng) in Pathumwan district was calculated by the ratio-sampling method as below.

$$
\mathrm{s}_{\mathrm{sub}}-\frac{n \times \mathrm{N}_{\text {sul }}}{\mathbb{N}}
$$

Where $n_{s w}=$ required sample size for the sub district, $n=$ required sample size for the district, $N_{s w \bar{z}}=$ population size of the sub district, and $N=$ population size of the district. As $n=381$ for Pathumwan district based on 2009 data (Department of Provincial Administration, 2009), 131 samples were required for Lumphinee sub-district $\left(N_{s w}=20,278\right), 130$ samples were required for Roungmuan sub-district $\left(N_{s \omega \bar{z}}=20,031\right), 70$ samples were required for Wangmai sub-district $\left(N_{s w \bar{\varepsilon}}=10,905\right)$, and 50 samples were required for Pathumwan sub-district $\left(N_{s w \bar{\varepsilon}}=7,644\right)$.

\section{Data Analysis}

\subsection{Descriptive Analysis}

Most of the respondents were female (56.7\%), completed undergraduate school (63.3\%), single (70.9\%), living in a single house (55.9\%), and having personal monthly income in a range of 10,001 to 20,000 Thai baht (41.7\%). The median age of the respondents was 28 years old. Of total 381 samples, 217 respondents (57\%) reported that they are involving in recycling activities while 231 respondents $(60.6 \%)$ reported that they have intention to recycle. The samples demonstrated appropriate representatives of Bangkok population which $52.4 \%$ is female, median age is a range of 20 to 34 years old, per capita income on average equal to 11,284 Baht (National Statistical Office and Office of the National Economic and Social Development Board, 2008). However, the sample group was better educated than the populations which have average years of educational attainment at 12 years (Office of Education Council, Ministry of Education, 2009).

\subsection{Principal Component Analysis}

Principal component analysis (PCA) was carried out prior to the analysis to examine the empirical dimensions of questionnaire data measured on ordinal scales (Jolliffe, 2002). To measure the competence of PCA to the initial variables, the Kaiser-Meyer-Olkin (KMO) statistic and the Bartlett's test was performed. The KMO measure of sampling adequacy provides an index ranges from 0 to 1 . A value close to 1 indicates that patterns of correlations are relatively compact and so factor analysis should yield distinct and reliable factors. The Bartlett's test evaluates whether the correlation matrix of initial variables is significantly different from the identity matrix. The PCA can be applied if the hypothesis that these matrixes are equal is rejected (Kaiser, 1974; Field, 2005).

The result of principle component analysis of 18 items showed no problematic collinearity across dimensions. $\mathrm{KMO}=0.772$ showed a modest sampling adequacy of factor analysis. The Bartlett's test is highly significant at p-value equal to .00, approved that the PCA is applicable. The factor loadings demonstrated 6 dimensions, in aggregate explained $91.46 \%$ of the total variance in the overall data. The dimensions were named into 6 components in accordance with contained items; 1) perceived space needed for recycling, 2) perceived facility condition, 3) adequacy of recycling information, 4) perceived time needed for recycling, 5) perceived personal recycling ability, and 6) perceived recycling habit, in order of percent of variance explained. The result of PCA is summarized in table 1. 
Table 1. Results of the principal component analysis

\begin{tabular}{|c|c|c|}
\hline Items & Loadings ${ }^{\text {a }}$ & $\%$ of Variance explained \\
\hline \multicolumn{3}{|l|}{ Component 1: Perceived space needed for recycling } \\
\hline I feel that recycling waste is space consuming & +0.957 & \multirow{3}{*}{30.86} \\
\hline I feel that storing recycle waste affects using space in my house & +0.944 & \\
\hline I feel that recycling waste is inconvenience in term of space & +0.933 & \\
\hline \multicolumn{3}{|l|}{ Component 2: Perceived facility condition } \\
\hline I feel that it is easy for me to find recycling service & +0.934 & \multirow{3}{*}{19.82} \\
\hline I agree that I am provided good recycling facility & +0.944 & \\
\hline I feel that recycling service is convenient to access. & +0.940 & \\
\hline \multicolumn{3}{|l|}{ Component 3: Adequacy of recycling information } \\
\hline I feel that am well provided information about recycling & +0.954 & \multirow{3}{*}{13.97} \\
\hline I often find recycling information commonly & +0.904 & \\
\hline I agree that I am accessible to information regarding recycling & +0.947 & \\
\hline \multicolumn{3}{|l|}{ Component 4: Perceived time needed for recycling } \\
\hline I feel that recycling waste is time consuming & +0.847 & \multirow{3}{*}{11.58} \\
\hline I feel that it takes times to separating recyclable waste from others & +0.922 & \\
\hline I feel that recycling waste is inconvenience in term of time & +0.925 & \\
\hline \multicolumn{3}{|l|}{ Component 5: Perceived personal recycling ability } \\
\hline I feel that I have ability to recycle waste properly & +0.920 & \multirow{3}{*}{8.57} \\
\hline I agree that it is not troublesome for me to sort recyclable waste & +0.917 & \\
\hline I think that I know well the process of recycling household waste & +0.890 & \\
\hline \multicolumn{3}{|l|}{ Component 6: Perceived recycling habit } \\
\hline I feel that I have a habit of recycling waste & +0.889 & \multirow{3}{*}{6.65} \\
\hline I agree that I recycle waste without consciousnesses & +0.909 & \\
\hline I think that I recycle waste because it is my habit & +0.918 & \\
\hline
\end{tabular}

${ }^{\text {a }}$ After Varimax rotation with Kaiser Normalization.

\subsection{Logistic Regression Analysis}

Logistic regression analysis was employed to estimate significant impacts of explanatory variables on recycling behavior. The logistic regression works with odds which refer to the ratio of proportions for the two possible outcomes (Gujrati, 1995; Long, 1997; Hosmer \& Lemeshow, 2000). If the probability of $Y=1$ is $P$ and 1-P is the probability when $Y=0$, the odds or the ratio of the probability of $Y=1$ to its complement could be defined as equation (1). Where $X$ refers to explanatory variables 1 to $\mathrm{k}$ and $i$ refers to samples 1 to $\mathrm{n}$. Since the odds can take any positive values and so have no ceiling restriction, a logistic transformation is applied to remove the floor restriction. A multiple logistic regression model is abbreviated as equation (2).

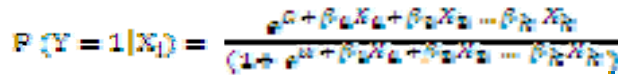

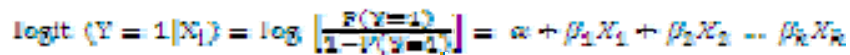

Parameters in logistic regression model are estimated by maximum likelihood method. The statistical significance of each coefficient is evaluated using the Wald test. The regression coefficient $\beta$ represents the change in the logit of the probability from a unit change in the associated predictor, holding other factors constant. The coefficients or the log-odds can also be interpreted after anti-log, by exponentiating, as the change in the ratio of probability of outcome $\mathrm{Y}=1$ over $\mathrm{Y}=0$ for a unit change in the associated explanatory factor, ceteris paribus (Gujrati, 1995; Long, 1997; Hosmer \& Lemeshow, 2000; Flom \& Strauss, 2003). The goodness-of-fit of the logistic regression models in this study was analyzed using a) the -2log-likelihood statistic, which measures unexplained variation in the model. The larger the value expresses the less accurate the predictions of the model; b) the Omnibus test, which is a likelihood-ratio chi-square test whether the coefficients of the variables in the model are all jointly equal to zero; c) the Hosmer \& Lemeshow goodness of fit test, which examines the null hypothesis that the model adjust well to the data; and d) the Nagelkerke $\mathrm{R}^{2}$, which reveals the amount of variation in the outcome variable that is explained by the model, having maximum value equal to 1 .

In the present study, $\mathrm{Y}=1$ is the probability that the respondent is a recycler. The explanatory variables consist of 7 factors; 1) perceived space needed for recycling, 2) perceived time needed for recycling, 3) perceived recycling facility condition, 4) perceived personal recycling ability, 5) adequacy of recycling information, 6) perceived recycling habit, and 7) the recycling intention variable, coded as dummy variable; $1=$ have intention to recycle, 
$0=$ have no intention to recycle. The variables 1 to 5 corresponded to the situational condition $(\mathrm{F})$ in the interpersonal model. Total 7 input variables were computed in two stages. The first stage was performed to test for the main effects of the promising predictors. The second stage was computed to investigate the trade off effect between habit and recycling intention.

The result of main effects in the first stage is summarized in table 2. Hosmer and Lemeshow test was insignificant indicated that the model fit well to the data. Omnibus test of model coefficients showed a significant contribution of the entered variables. The -2log-likelihood equaled to 133.157 . Nagelkerke $\mathrm{R}^{2}$ equaled to .857 , revealed that the amount of variation in the outcome variable was well explained by the model. Perceived facility condition, perceived personal recycling ability, perceived adequacy of recycling information, recycling intention, and habit were significantly predicted recycling behavior. The largest impact was found on recycling intention; follow by the habit, perceived personal recycling ability, perceived facility condition and perceived adequacy of recycling information respectively. Respondents who have intention to recycle, have stronger recycling habit, feel satisfied with facility condition, have adequate recycling information, and believed that they have ability to recycle, are likely to participate in recycling.

Table 2. Results of logistic regression analysis of the main effects

\begin{tabular}{|c|c|c|c|c|c|c|c|}
\hline Predictors & $\mathrm{B}$ & S.E. & Wald & df & \multicolumn{2}{|c|}{ Sig. } & $\operatorname{Exp}(B)$ \\
\hline Perceived space needed for recycling & .231 & .253 & .833 & 1 & .361 & & 1.259 \\
\hline Perceived time needed for recycling & -.045 & .258 & .030 & 1 & .862 & & .956 \\
\hline Perceived facility condition & .740 & .199 & 13.850 & 1 & .000 & $* *$ & 2.096 \\
\hline Perceived personal recycling ability & .966 & .490 & 3.878 & 1 & .049 & * & 2.627 \\
\hline Adequacy of recycling information & .739 & .341 & 4.699 & 1 & .030 & $*$ & 2.094 \\
\hline Recycling Intention & 4.711 & .608 & 60.002 & 1 & .000 & $* *$ & 111.130 \\
\hline Habit & 1.752 & .635 & 7.607 & 1 & .006 & $* *$ & 5.768 \\
\hline
\end{tabular}

Dependent variable $=$ Recycling Behavior $(1=$ recycler, $0=$ non recycler $)$

$\operatorname{Exp}(\beta)=$ Exponent of $\beta$.

Statistically significant at the $* 0.05$ and $* * 0.01$ level.

The tradeoff between intention and habit was investigated in second stage by injecting interaction terms of habit with the other 6 predictors into the model. The result of the regression analysis is summarized in table 3 . Hosmer and Lemeshow test was insignificant. Omnibus test of model coefficients showed a significant contribution of the entered variables. Nagelkerke $\mathrm{R}^{2}$ equaled to .874 . The $-2 \log$-likelihood equaled to 119.319 . The interaction term of habit and recycling intention was found significant at .05 significant level. A significant negative moderating effect of habit on recycling intention verified that there is a tradeoff between the level of habit and recycling intention on recycling behavior. Higher level of habit resulted in a reduction in the intention needed to make a decision to recycle.

Table 3. Results of logistic regression analysis after inclusion of interaction terms

\begin{tabular}{|c|c|c|c|c|c|c|c|}
\hline Predictors & B & S.E. & Wald & df & Sig. & & $\operatorname{Exp}(B)$ \\
\hline Perceived space needed for recycling & .463 & .334 & 1.926 & 1 & .165 & & 1.590 \\
\hline Perceived time needed for recycling & .166 & .360 & .213 & 1 & .644 & & 1.181 \\
\hline Perceived facility condition & .920 & .268 & 11.787 & 1 & .001 & $* *$ & 2.510 \\
\hline Perceived personal recycling ability & .506 & .645 & .614 & 1 & .433 & & 1.658 \\
\hline Adequacy of recycling information & .672 & .454 & 2.186 & 1 & .139 & & 1.958 \\
\hline Recycling Intention & 6.142 & 1.127 & 29.697 & 1 & .000 & $* *$ & 465.034 \\
\hline Habit & 3.883 & 1.307 & 8.822 & 1 & .003 & $* *$ & 48.577 \\
\hline Habit * perceived space needed for recycling & -.601 & .607 & .978 & 1 & .323 & & .548 \\
\hline Habit $*$ perceived time needed for recycling & -.471 & .596 & .626 & 1 & .429 & & .624 \\
\hline Habit $*$ perceived facility condition & -.526 & .427 & 1.517 & 1 & .218 & & .591 \\
\hline Habit * perceived personal recycling ability & .818 & .997 & .673 & 1 & .412 & & 2.266 \\
\hline Habit * adequacy of recycling information & .350 & .804 & .190 & 1 & .663 & & 1.419 \\
\hline Habit $*$ recycling intention & -3.167 & 1.498 & 4.468 & 1 & .035 & $*$ & .042 \\
\hline
\end{tabular}

Dependent variable $=$ Recycling Behavior $(1=$ recycler, $0=$ non recycler $)$

$\operatorname{Exp}(\beta)=$ Exponent of $\beta$.

Statistically significant at the $* 0.05$ and ${ }^{* *} 0.01$ level. 


\subsection{Comparable Analysis}

To test whether there is a significant difference in relationship between the predictors and recycling behavior across degrees of habit, the research grouped 6 levels of perceived habit levels in to two groups (score 1 to $3=$ weak habit, score 4 to $6=$ strong habit). Of total 381 samples, 297 respondents $(78 \%)$ classified as relative weak habit respondents, where 84 respondents $(22 \%)$ clarified as relative strong habit respondents. A Spearman's Rank Order correlation was run to determine the relationship between recycling behavior and the predictors (recycling intention, facility condition, recycling ability, and recycling information) of the two groups. To test the statistical significance of the difference between correlations between the two groups, the rho correlation coefficients or $r$ values obtained from both groups were firstly converted into a standard score form (z scores). This is done primarily to ensure that the sampling distributions are approximately normal. Next, the observed $\mathrm{z}$ value was calculated using the following formula (Pallant, 2007).

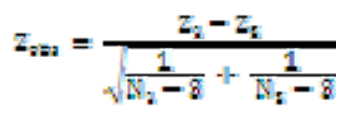

If obtained $z_{o b s}$ value is between -1.96 and +1.96 at $\mathrm{p}=.05$ or between -2.58 and +2.58 at $\mathrm{p}=.01$ then there is no statistically significant difference between the two correlation coefficients. The result of the analysis is demonstrated in table 4. The correlation of recycling behavior and recycling intention of the weak habit group was significantly stronger than the strong habit group $\left(r_{\text {weak }}=.903, r_{\text {strong }}=.511, z_{\text {obs }}=7.392\right)$. For those with relative high recycling habit, their recycling action is likely to be less associated with the intention. The same outcome was also found in correlation between recycling behavior and recycling facility condition. Recycling behavior for the weak habit group is significantly more related to the condition of the facility than the strong habit group $\left(r_{\text {weak }}=.770, r_{\text {strong }}=.311, z_{\text {obs }}=5.592\right)$. For those with relative high recycling habit, their recycling decision tends to be less associated with the recycling facility condition. In contrast, though a significant correlation between recycling behavior and recycling ability was found in both weak habit and strong habit groups $\left(r_{\text {weak }}=.413\right.$, $\left.r_{\text {strong }}=.268\right)$, there was no significant difference in relationship between the two groups $\left(z_{o b s}=1.32\right)$. In addition, a significant correlation between recycling behavior and the adequacy of recycling information was found only in weak habit group $\left(r_{\text {weak }}=.363\right)$. The result indicated that recycling participation of those with weaker recycling habit tends to be fairly involved with adequacy of recycling information, whereas recycling action for those with relative strong recycling habit is unlikely to be engaged in sufficiency of recycling information.

Table 4. Correlation coefficients between recycling behavior and predictors

\begin{tabular}{|c|c|c|c|c|c|c|}
\hline Relationship & Weak Habit gr & & Strong Habit & oup & $\mathrm{Z}_{\mathrm{obs}}$ & \\
\hline Behavior-Intention & $\begin{array}{r}.903 \\
(1.488) \\
\end{array}$ & $* *$ & $\begin{array}{r}.511 \\
(.564) \\
\end{array}$ & $* *$ & 7.392 & ** \\
\hline Behavior-Facility condition & $\begin{array}{r}.770 \\
(1.020) \\
\end{array}$ & ** & $\begin{array}{r}.311 \\
(.321) \\
\end{array}$ & $* *$ & 5.592 & $* *$ \\
\hline Behavior-Recycling ability & $\begin{array}{r}.413 \\
(.439) \\
\end{array}$ & $* *$ & $\begin{array}{r}.268 \\
(.274) \\
\end{array}$ & $*$ & 1.320 & \\
\hline Behavior-Recycling information & $\begin{array}{r}.363 \\
(.380)\end{array}$ & $* *$ & $\begin{array}{r}.189 \\
(.191)\end{array}$ & & 1.512 & \\
\hline
\end{tabular}

Statistically significant at the $* 0.05$ and $* * 0.01$ level.

$\mathrm{N}$ weak $=297, \mathrm{~N}$ strong $=84$

( $\mathrm{Z}$ standard score)

\section{Conclusion and Discussion}

The outcomes of the study presented an important role of habit on recycling behavior of Thai household. Habit was found to provide a second large impact on recycling behavior of the respondents after recycling intention. Besides, the trade-off relationship between recycling habit and recycling intention was significant. The negative moderating effect of habit on recycling intention signified that when people have stronger habit of recycling, they are likely to recycle waste without consciousness or intention. As repeating the same activity given a same stable supporting context would most likely develop skill acquisition, thus recycling could be performed easier with minimum effort. Moreover, recycling practice would probably become automatic once the repetition and skill eliminate the weight of focal attention and pass to the actual behavior without intention. That is, higher recycling habit would probably allow people to recycle with less reliance on the social influence, personal preference, and expectation of the consequences which are subjects account for the intention. Furthermore, 
recycling behavior of people with stronger recycling habit tends to be less related to the satisfaction on recycling facilities and the information. Therefore, recycling habit possibly conquers the obstacles from attitudinal and situational factors.

Promoting recycling habit among Thai people to improve recycling participation would be an imperative challenge for future policies. Creating a habit is not simple, but still possible. An important condition for habit to develop is to provide people an ability to repeat the activity and built it into daily agenda. This is fundamental because habit strength is assumed to be correlated positively with behavior repetition. A standard recycling facility should be provided with a proper instruction. The process should be simple and easy to continue. The program should particularly concentrated on forming recycling habit among children since it is easier to build a habit in an early state.

A limitation of the present study that is worth to note is the possible bias form self-reported and self-evaluated data. Alternative survey methods such as an observation or a diary report might be comprised to overcome the constraint in the future research.

\section{References}

Barr, S. (2002). Household Waste in Social Perspective: Values, Attitudes, Situation and Behavior. Hampshire: Ashgate Publishing Company.

BMA data center. (2009). Bangkok Metropolitan Administration, Thailand. Retrieved from http://203.155.220.118/info/Default.asp

Boldero, J. (1995). The prediction of household recycling of newspapers: The role of attitudes, intentions, and situational factors. Journal of Applied Social Psychology, 25, 440-462. http://dx.doi.org/10.1111/j.1559-1816.1995.tb01598.x

Carrus, G., Passafaro, P., \& Bonnes, M. (2008). Emotions, habits and rational choices in ecological behaviours: the case of recycling and use of public transportation. Journal of Environmental Psychology, 28, 51-62. http://dx.doi.org/10.1016/j.jenvp.2007.09.003

Chen, M., \& Tung P. (2010). The Moderating Effect of Perceived Lack of Facilities on Consumers' Recycling Intentions. Environment and Behavior, 42, 824-844. http://dx.doi.org/10.1177/0013916509352833

Chu, P.-Y., \& Chiu, J.-F. (2003). Factors influencing household waste recycling behavior: Test of an integrated $\begin{array}{lllll}\text { model. Journal of Applied Social } & \text { Psychology, } & \text { 33, }\end{array}$ http://dx.doi.org/10.1111/j.1559-1816.2003.tb01915.x

Cronbach, L. (1951). Coefficient alpha and the internal structure of tests. Psychometrika, 16, 297-334. http://dx.doi.org/10.1007/BF02310555

Danner, U. N., Aarts, H., \& de Vries, N. K. (2008). Habit vs. intention in the prediction of future behavior: The role of frequency, context stability and mental accessibility of past behavior. British Journal of Social Psychology, 47, 245-265. http://dx.doi.org/10.1348/014466607X230876

Department of Provincial Administration, Ministry of Interior, Thailand. The 2009 population and housing census Retrieved from http://www.dopa.go.th

Field, A. (2005). Discovering statistics using SPSS (2nd ed.). Thousand Oaks: Sage.

Flom, P.L., \& Strauss, S. M. (2003). Some graphical methods for interpreting interactions in logistic and OLS regression. Multiple Linear Regression Viewpoints, 29, 1-7.

Gujrati, D.N. (1995). Basic econometrics (3rd ed.). New York: McGraw-Hill Book Company.

Hosmer, D., \& Lemeshow, S. (2000). Applied Logistic Regression. New York: John Wiley and Sons. http://dx.doi.org/10.1002/0471722146

Jolliffe, I.T. (2002). Principal Component Analysis (2nd ed.). New York: Springer-Verlag.

Kaiser, H. (1974). An index of factorial simplicity. Psychometrika, 39, 31-36. http://dx.doi.org/10.1007/BF02291575

Knussen, C., \& Yule, F. (2008). 'I'm not in the habit of recycling': The role of habitual behavior in the disposal of household waste. Environment and Behavior, 40, 683-702. http://dx.doi.org/10.1177/0013916507307527

Krejcie, R.V., \& Morgan, D.W. (1970). Determining sample size for research activities. Educational and Psychological Measurement, 30, 607-610. 
Laroche, M., Toffoli, R., Kim, C., \& Muller, T. E. (1996). The influence of culture on pro-environmental knowledge, attitudes, and behavior: A Canadian perspective. In K. P. Corfman \& J. Lynch (Eds.), Advances in consumer research. Provo, UT: Association for Consumer Research.

Long, J. (1997). Regression models for categorical and limited dependent variables. London: Sage.

National Statistical Office and Office of the National Economic and Social Development Board, Office of the Prime Minister, Thailand. Core Economic Indicators of Thailand 2008. Retrieved from http://service.nso.go.th/nso/nsopublish/indicator/indEco51.pdf

Office of Education Council, Ministry of Education, Thailand. Average Years of Educational Attainment of Thai Population 2009. Retrieved from http://www.onec.go.th/onec_administrator/uploads/Book/991-file.pdf

Ouellette, J. A., \& Wood, W. (1998). Habit and intention in everyday life: The multiple processes by which past behavior predicts future behavior. Psychological Bulletin, 124, 54-74. http://dx.doi.org/10.1037//0033-2909.124.1.54

Pallant, J. (2007). SPSS survival manual (3rd. ed.). New York: Open University Press.

Pollution Control Department (PCD), Ministry of Natural Resources and Environment. Thailand State of Pollution Report 1993-2009. Bangkok: Rungsilp printing.

Ronis, D. L., Yates, J. F., \& Kirscht, J. P. (1989). Attitudes, decisions, and habits as determinants of repeated behavior. In Pratkanis, A. R., Breckler, S. J. \& Greenwald, A. G. (Eds.), Attitude Structure and Function. Hillsdale, NJ: Lawrence Erlbaum.

Shapkota, P., Coowanitwong, N., Visvanathan, C., \& Trankler, J. (2006). Potentials of recycling municipal solid waste in Asia vis-a-vis Recycling in Thailand. SEA-UEMA Project, 195-229.

Shiffrin, R. M., \& Schneider, W. (1977). Controlled and automatic human information processing: II. Perceptual learning, automatic attending, and a general theory. Psychological Review, 84, 127-190. http://dx.doi.org/10.1037/0033-295X.84.2.127

Taylor, S., \& Todd, P. (1995). Understanding Household Garbage Reduction Behavior: A Test of an Integrated Model. Journal of Public Policy \& Marketing, 14, 192-204.

Tonglet, M., Phillips, P.S., \& Read, A.D. (2004). Using the theory of planned behavior to investigate the determinants of recycling behavior: A case study from brixworth, UK. Resources, Conservation and Recycling, 41, 191-214. http://dx.doi.org/10.1016/j.resconrec.2003.11.001

Triandis, H. C. (1977). Interpersonal behavior. Monterey, CA: Brooks/Cole Publishing Company.

Valle, P., Reis, E., Menezes, J., \& Rebelo E. (2004). Behavioral Determinants of Household Recycling Participation: The Portuguese case. Environment and Behavior, 36, 505-540. http://dx.doi.org/10.1177/0013916503260892

Verplanken, B., Aarts, H., van Knippenberg, A., \& van Knippenberg, C. (1994). Attitude versus general habit: Antecedents of Travel Mode Choice. Journal of Applied Social Psychology, 24, 285-300. http://dx.doi.org/10.1111/j.1559-1816.1994.tb00583.x 